\title{
The Oral and Dental Health Status in Children Under Haemodialysis
}

\author{
Shady Ahmed Moussa BDS, MSc, DDS, MRACDS (DPH) ${ }^{1 *}$, Nawras Maher Mostafa ${ }^{2}$ and Ahmed Aoun ${ }^{3}$ \\ ${ }^{1}$ Department of Pediatric Dentistry, Zigzag University, Egypt, (PHCC, Qatar) \\ ${ }^{2}$ Department of Restorative Dentistry, Iraq, (PHCC, Qatar) \\ ${ }^{3}$ Department of Pediatric Medicine, Medical School, Cairo University, Egypt (PHCC, Qatar)
}

*Corresponding author: Shady Ahmed Moussa, Department of Pediatric Dentistry, Zigzag University, Egypt, (PHCC, Qatar)

\begin{abstract}
Untreated dental infection in End Stage Renal Disease (ESRD) patients can potentially contribute to morbidity and transplant rejection. There is a need for detailed assessment and provision of good dental care following the diagnosis of chronic renal failure (CRF). Hence, regular clinical review is important for the early identification of oral complications of renal disease.
\end{abstract}

Aim: The present study was carried out at Pediatric Nephrology Unit in Zigzag University Hospital to evaluate the dental health status in CRF children.

Design: The dental health status of 50 children under 15 years suffering from CRF were compared results to the results of an age and sex matched control group $(\mathrm{n}=50)$. This study was done to evaluate enamel hypoplasia, dmft, DMFT, Gingival Index (GI), Plaque Index (PI), intrinsic and extrinsic stain and the changes in oral microflora including salivary Calcium, phosphorus, alkaline phosphatase and urea concentrations were measured using phenol Sulphur acid colorimetric method. The estimated stimulated salivary $\mathrm{pH}$, buffering capacity and count of Streptococcal Mutants and lactobacilli were determined on selective media of all participants.

Results: The study and control groups did not significantly differ in daily tooth brushing frequency and periodic dental check up frequency. Severe enamel hypoplasia was present in study group. The means of dmft, DMFT and PI were significantly greater in the study group $(\mathrm{p}<0.05)$. The differences among groups for GI were statistically insignificant. Our findings of intrinsic brown staining were $22 \%$ and $20 \%$ extrinsic staining of patients.

Conclusion: The salivary $\mathrm{pH}$ of patients and salivary levels of cariogenic S. mutans and lactobacilli in the study group were significantly lower than the control group, probably due to increased concentrations of antibacterial chemicals such as urea in the saliva of CRF children. The presence of uremia during the development of dentitions cause Intrinsic staining but black brown extrinsic staining due to using ferrous sulfate syrup for treatment CRF children anemia. Although dental treatment need is not high, these children should receive dental health education, including oral hygiene instruction, in order to improve their overall oral health.

Keywords: End Stage Renal Disease Orthodontic; Chronic Renal Failure; Dental; Streptococcal Mutans; Caries; Children; Haemodialysis

\section{Introduction}

Chronic kidney disease (CKD) is a major health problem worldwide with increasing incidence and prevalence that is threatening to bring on the onset of a real 'epidemic and characterized by a gradual loss of kidney function over time [1-3]. Childhood CKD presents clinical features that are specific and totally peculiar to the paediatric age, such as the impact of the disease on growth. In addition, some of the typical characteristics of paediatric CKD, such as the etiology or cardiovascular complications, represent variables, not only influencing the health of the patient during childhood, but also having an impact on the life of the adult 
that this child will become. CKD in children is a major problem of public health both in poor and developed countries and it is an important cause of morbidity and mortality in children worldwide $[4,5]$. There is limited information on the epidemiology of CKD in the pediatric population due to the absence of a common definition and well-defined classification [6]. According to ItalKid Project, a prospective, population-based Italian study on CKD epidemiology, and the North American Pediatric Renal Trials and Collaborative Studies (NAPRTCS), CKD was defined as having a glomerular filtration rate (GFR) of below $75 \mathrm{ml} / \mathrm{min} / 1.73 \mathrm{~m} 2$ [7,8]. While other authors based their definition on serum creatinine levels themselves or on other thresholds of GFR $[9,10]$. The National Kidney Foundation's Kidney Disease Outcomes Quality Initiative (NKF-K/ DOQI) published a guideline on CKD, which included a classification system for CKD severity, independent of cause, and applicable to children. This classification system identifies five stages of CKD based on the level of GFR. CKD is now defined by the presence of kidney damage (for example, any structural or functional abnormality involving pathological, laboratory or imaging findings) for $\geq 3$ months or a GFR $<60 \mathrm{ml} / \mathrm{min} / 1.73 \mathrm{~m}^{2}$ for $\geq 3$ months [11]. CKD causes are different between children and those in adults. The congenital causes, including congenital anomalies of the kidney and urinary tract (CAKUT) (48\%) which is predominated in younger patients and hereditary nephropathies (10\%), were the most common. Glomerulonephritis accounts for $14 \%$ of cases which is the leading cause in children older than 12 years of age and there are variations of the cause's distribution with ages and races, according to NAPRTCS annual report [12]. According to United States Renal Data System (URDS) Registry, the congenital disorders (CAKUT and hereditary nephropathies) were the most common etiologies in the youngest ESRD group, whereas the proportion of acquired diseases increased progressively with age [13]. The similar distribution of causes of CKD has been reported in Europe, where the proportions of CAKUT and hereditary nephropathies were $58-59 \%$ and $15-19 \%$, respectively. The proportion of glomerulonephritis was (5-7\%) which was lower than United States that's could be due to the difference in racial distribution [14]. CAKUT is the leading cause of CKD (47$62 \%$ ) with clear predominance of uropathies over hypo dysplasia followed by hereditary nephropathies (17 to 30\%) in Middle East $[10,15]$. But the neuropathic bladder remained an important cause of CKD in Turkey (15\%) than other Middle East communities [16]. The prevalence of dialysis patients in Egypt is presumed to have increased from 10 per million population (pmp) in 1974 to about 165 (pmp) in 1995 and more recent study showed a further increase in CRF prevalence to 225 (pmp) in 1999 [17]. The highest prevalence was 483 (pmp) in 2004 as reported by Afifi et al. [18] in the ninth annual scientific meeting of the Egyptian Renal Registry in 2008. Most CRF patients are treated by haemodialysis, as reported in different studies $[18,19]$. The chronic glomerulonephritis is the main reported cause of CKD in various studies and this may be related to high prevalence of bacterial, viral, and parasitic infections that commonly affect the kidneys in developing countries, as well as a different age distribution dies from Southeast Asia, Latin America and Caribbean area with a prevalence ranging from 30 to almost $60 \%[20,21]$. The CAKUT are the main causes, accounting for (34$43 \%$ ) of pediatric ESRD cases in Europe, Japan, Australia, and New Zealand. The proportion of ESRD caused by glomerulonephritis was lower in Europe according to the ESPN/ERA-EDTA registry (15\%) compared with a Japanese study (22\%) and the Australia and New Zealand Dialysis and Transplant Registry (ANZDATA) this may be due to the age distribution of patients, with fewer young patients being treated for ESRD at that time [22,23].

\section{Clinical Features of CKD in Children}

Growth impairment is a common and perhaps the most visible complication of CKD in children and its increase as GFR declines, even though a significant decrease in growth was seen at all levels of kidney function [1,24-26]. In children with CKD the risk factors that contribute to impaired growth include: malnutrition, metabolic acidosis, mineral and bone disorders, anaemia, and fluid and electrolyte abnormalities $[27,28]$. That's making the inadequate nutrition (due to anorexia or vomiting) appears to be the most important factor contributing to growth impairment at that age and maximizing caloric intake to at least $80 \%$ of requirements has been found to effectively improve growth in children who developed CKD as infants [29]. Anemia is one from the most a common complication in children with CKD causing many adverse clinical consequences such as; poor quality of life, depressed neurocognitive ability, reduced exercise capacity and progression of cardiovascular risk factors, such as left ventricular hypertrophy (LVH) [30,31]. However the diagnosis of anemia in children with CKD is not as straightforward and its $s$ in prevalence with advancing stages of CKD. Anemia of CKD is the result of many interacting factors, but decreased production of erythropoietin by the unhealthy kidney and iron dysregulation (including iron deficiency and iron-restricted erythropoiesis) are the primary defects [32]. The hypertension can be present from the earliest stages of the disease and its prevalence increases as GFR progressively declines [33,34]. effective control of BP reduces not only cardiovascular morbidity and mortality, but also the rate of progression of CKD [35]. The CKD have significantly increased rates of cardiovascular morbidity and mortality in both adult and paediatric compared to the general populations [36,37]. For paediatric population with CKD the risk reach 1000 times higher in the ESRD group compared with the age-matched non-CKD population [38]. CVD in the CKD population ensues from a combination of traditional (e.g. hypertension, dyslipidaemia, abnormal glucose metabolism and obesity) and CKDrelated risk factors (e.g. increased calcium-phosphorus product, hyperparathyroidism and anemia) [34] and there are evidences that the cardiovascular anomalies begin early in the course of renal failure, irrespective of the age of onset, and rapidly progress when dialysis is initiated [39]. Chronic kidney disease-mineral and bone disorder (CKD-MBD) is defined by the presence of one or a 
combination of the following findings: abnormalities in calcium, phosphorus, parathyroid hormone (PTH) or vitamin D metabolism; abnormalities in bone histology, linear growth, or strength; vascular or other soft tissue calcifications [40]. The Renal osteodystrophy is an aspect of CKD-MBD that refers only to bone pathology. The changes in calcium and phosphorus metabolism can significantly alter bone remodeling and somatic growth making the optimization of bone health, growth and final adult height must be a focus of CKD management in children [41]. The effective treatment of CKD-MBD affects the progression of cardiovascular disease, as phosphate is also a strong vascular toxin either or through its effect on PTH and fibroblast growth factor 23 [42,43]. Progressive loss of renal function causes retention of excretory products leading to uremia and azetomia [44]. Azetomia is an increase in blood urea nitrogen (BUN) may be associated with adverse clinical signs and symptoms to produce uremia that is with malnutrition resulting from a protein-restricted diet leads to an immune deficient state resulting in a significant impaired host deficiency and higher susceptibility to infection [45]. Dialysis patients may form calculus more rapidly than healthy individuals may possibly due to high salivary urea and phosphate levels. Calculus is always covered with a non-mineralized layer of plaque [46]. Renal failure is also associated with a reduced prevalence of caries, and its early intraoral symptoms include bad metallic taste and ammonia odor. Loss of lamina dura, loosening of teeth, bony fractures, bone tumors, radiolucent cyst-like lesions, malocclusion, narrow pulp chamber, and thick pre-dentin may also be seen in these patients $[47,48]$. Davidovich et al. [49] reported that, the patients suffering from (ESRF) and those receiving dialysis are more prone to periodontal disease and other oral health problems. The renal failure patients had higher gingival index (GI) and bleeding; probing depths, attachment loss, hypoplasia, obliteration and less caries. The plaque was found to be higher in the dialysis and pre-dialysis patients than the normal. Infections in the oral cavity may act as foci for disease or injury in other sites of the body [50]. Many researchers have investigated the salivary content and flow rate in adults with CRF. Significantly, higher concentrations of salivary proteins, potassium and sodium were observed in unstimulated saliva collected from adults undergoing haemodialysis compared with healthy volunteers [51]. Others reported that the $\mathrm{pH}$ and buffer capacity of the unstimulated saliva was also increased in haemodialysis patients [52]. Various authors examined the relationship between the composition of saliva and cariogenic activity and the control of inflammatory processes of the mouth. A rise in the levels of free radicals (reactive oxygen species) has been found to be the common factor in these processes [53]. Untreated dental infection in immunosuppressed individuals can potentially contribute to morbidity and transplant rejection [54]. There is a need for detailed assessment and provision of good dental care following the diagnosis of chronic renal failure (CRF) so that, regular clinical review is important for the early identification of oral complications of renal disease $[55,56]$. Advances in pediatric nephrology during the last two decades have resulted in a marked increase in the number of children surviving with CRF. Considering the consequences of oral health concerns for children with CRF and ESRD, the present study was conducted to gain further insight into oral microflora changes of these patients in comparison with the healthy control group (Figure 1).

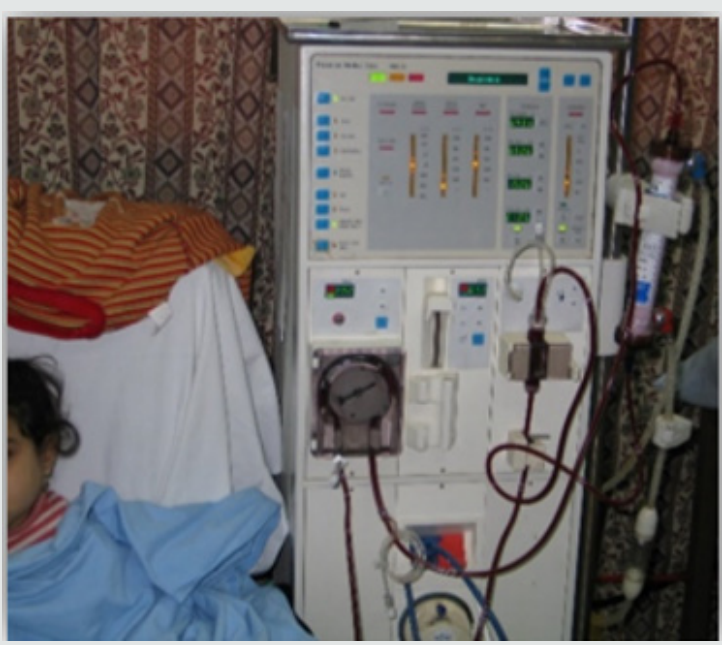

Figure 1: 8 years old child with ESRD on haemodialysis machine.

\section{Subjects and Methods}

Table 1: Primary kidney disorders in children with end-stage renal disease (ESRD).

\begin{tabular}{|c|c|}
\hline Diagnosis & No. of subjects \\
\hline Chronic glomerulonephritis & 5 \\
\hline Steroid resistant nephritic syndrome & 2 \\
\hline Hypoxic glomerulopathy & 6 \\
\hline Obstructive uropathy & 5 \\
\hline Interstitial nephropathy & 1 \\
\hline Renal amyloidosis & 2 \\
\hline Rapidly progressive glomerulonephritis & 5 \\
\hline Chronic interstitial nephritis & 4 \\
\hline Toxic nephropathy & 11 \\
\hline Acute tubular necrosis & 1 \\
\hline Unknown & \\
\hline
\end{tabular}

According to World Medical Association, declaration of Helsinki [57], study population and ethical local institutional approval for study in this cross-sectional study sample comprised 100 participants with the same socioeconomic conditions and aged from 2-15 years. Control group (G1) was composed of 50 healthy randomly selected individuals whose were scheduled for treatment at (Outpatient Dental Clinics, Zigzag University Hospital, Egypt). Patients with debilitating diseases or neurological disorder or who examined for possible ear infections were excluded from the study. Another study group (G2) consisted of $50 \mathrm{CRF}$ patients were undergoing regular haemodialysis treatment in the paediatric 
nephrology unit at Zigzag University Hospital, Egypt which their information retrieved from their files, patients were categorized according to the primary kidney disorder (Table 1). No other systemic disease was diagnosed in any of these patients. All parents or legal guardians received adequate information and written consent to participate in the study. The study did not include any invasive technique leading to contamination to or from these patients. The same examiner performed the clinical examination and allocated participants in both groups blindly.

\section{Clinical Examinations}

The examination of each patient was carried out using a mouth mirror and a probe according to the criteria of the World Health Organization [58,59]. Each subject was assessed for daily tooth brushing frequency and periodic dental checkup frequency. Following a general appraisal of the mouth, the teeth were examined in both study and control groups for tooth caries, hypoplasia, discolorations, gingival status, and plaque indices.

a) Caries Status: Determined by recording the number of decayed (d, D), missing ( $m, M)$, and filled (f, F) teeth in the primary and permanent dentitions for each patient and were referred to as dmft for primary teeth and DMFT for permanent teeth.

b) Dental Plaque Recording: The deposits were assessed using the Plaque Index. The children were asked for crushing the disclosing tablet or applying disclosing solution for young children and the plaque assessed by numerical scoring of plaque (PI) Plaque Index [60] (Table 2).

Table 2:

\begin{tabular}{|c|c|}
\hline Score & Description of Plaque Index (PI) \\
\hline 0 & No plaque in gingival area. \\
\hline 1 & $\begin{array}{c}\text { A film of plaque adhering to free gingival margin and adjacent } \\
\text { area of tooth that may be recognized only by running probe } \\
\text { across the tooth surface. }\end{array}$ \\
\hline 2 & $\begin{array}{c}\text { Moderate accumulation of soft deposits within gingival } \\
\text { margin and } \backslash \text { or adjacent tooth surface that can be seen naked } \\
\text { eye. }\end{array}$ \\
\hline 3 & $\begin{array}{c}\text { Abundance of soft matter within the gingival pocket and } \backslash \text { or } \\
\text { on gingival margin adjacent tooth surface. }\end{array}$ \\
\hline
\end{tabular}
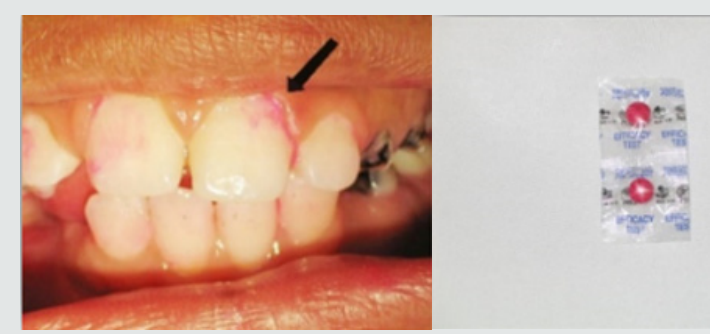

Figure 2: Painted teeth after using disclosing tablets to detect amount of plaque on teeth surfaces.

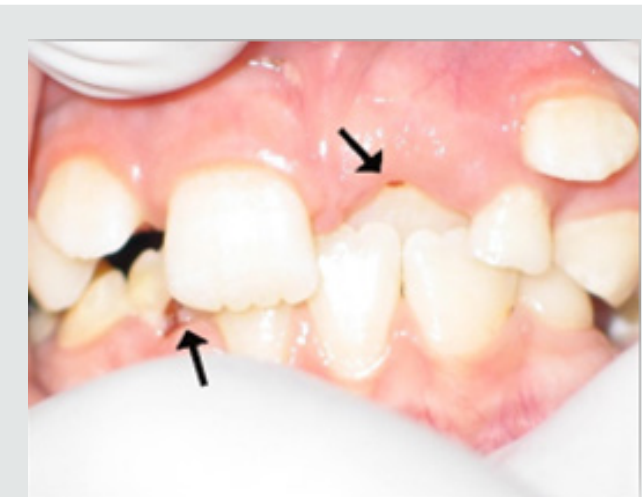

Figure 3: Gingiva of child suffer from CRF from one a year ago with pale gingival color but can bleed easily.

c) Gingivitis Recording: The gum status was assessed using the Gingival Indices The gingiva were examined for inflammation using a Gingival Index (GI) by using mouth mirror and blunt periodontal explorer [61] (Table 3).

Table 3:

\begin{tabular}{|c|c|}
\hline Score & Description of Gingival Index (GI) \\
\hline 0 & Normal gingiva \\
\hline 1 & $\begin{array}{c}\text { Mild inflammation, slight change in color, slight edema, no } \\
\text { bleeding on palpation. }\end{array}$ \\
\hline 2 & $\begin{array}{r}\text { Moderate inflammation, redness, edema, and glazing, } \\
\text { bleeding on palpation. }\end{array}$ \\
\hline 3 & $\begin{array}{r}\text { Sever inflammation, marked redness and edema, ulceration, } \\
\text { tendency to spontaneous bleeding. }\end{array}$ \\
\hline
\end{tabular}

d) Discolorations Recording: Detect any discoloration on the teeth of child and differentiate if it was black or brown extrinsic stain or brown intrinsic stain.

e) Enamel Hypoplasia Recording: Enamel hypoplasia was assessed as (none, mild, moderate, sever) using the criteria determined by Alaluusa et al. [62] (Table 4).

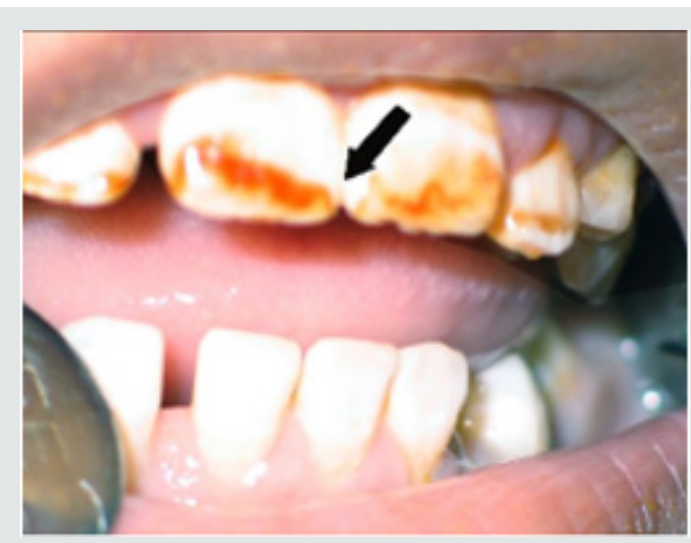

Figure 4: Teeth of CRF child with sever enamel hypoplasia \& intrinsic discoloration. 
Table 4:

\begin{tabular}{|c|c|}
\hline Type & The criteria of enamel hypoplasia \\
\hline None & No teeth with enamel hypoplasia. \\
\hline Mild & One or two teeth with small enamel defect (localized). \\
\hline Moderate & More than two teeth with enamel defect. \\
\hline Sever & Most or all of teeth with enamel defects (generalized). \\
\hline
\end{tabular}

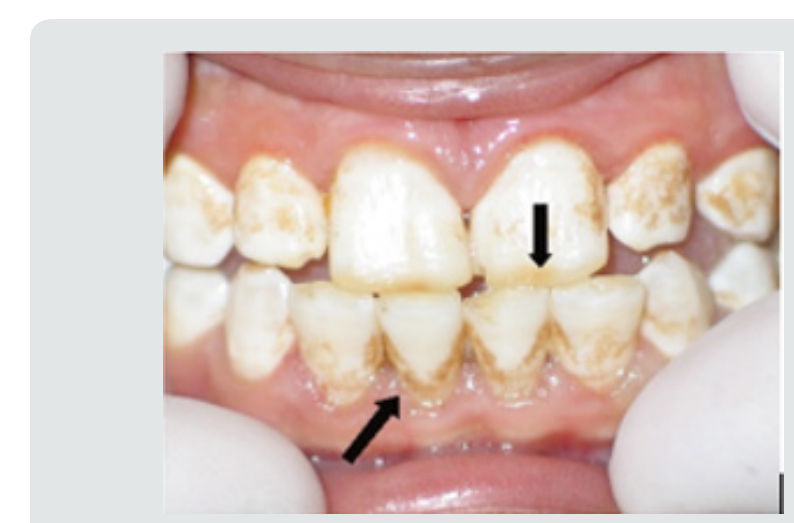

Figure 5: Teeth of CRF child with mild enamel hypoplasia, intrinsic \& extrinsic discoloration.

\section{Salivary Tests}

Children in both groups should be without any antibiotic therapy in the last week before the sample collection. For measuring the Streptococcus mutans (S. mutans) and lactobacilli count in saliva by means of selective culture media. Before collecting saliva for the bacteriological counting test, the patients were asked not to eat or drink for at least an hour and salivation was stimulated by having the children chew a paraffin pellet for 5 minutes. About $5 \mathrm{ml}$ of the saliva from each child was collected in a sterile calibrated container. The containers were stored in ice for transfer and kept frozen at $-80^{\circ} \mathrm{C}$ until the time of assay. Each sample was divided into three separate samples in sterile tubes, two of them inoculated onto selective media while the samples was taken. Bacterial counts from each of the different media were obtained and compared. The third sample processed for detect level of salivary calcium (Ca), phosphorus $(\mathrm{pH})$, alkaline phosphatase (AP), salivary urea and salivary $\mathrm{pH}$.

a) Streptococcal Mutans count (S. Mutans): About 3ml from saliva samples which collected were stored in a sterile calibrated universal container that were divided into two separate parts of samples, one of them inoculated onto Mitis Salivarius agar media (Becton Dickinson and DIFCO Company, Chicago, USA) was used for isolation S. Mutans that is the selective medium [63]. (Figure 6) Mitis salivarius agar media contents: (Pancreatic digest of casein 6gm, Proteose peptone 9gm, Proteose peptone 5gm, Saccharose 50gm, Dextrose 1gm, Dipotassium phosphate 4gm, Trypan blue $0.075 \mathrm{gm}$, Crystal violet $0.008 \mathrm{gm}$ and Agar 15gm) after the samples were taken. The medium was prepared according the manufacturing instructions as: $90 \mathrm{gm}$ of the medium and $150 \mathrm{gm}$ sucrose were dissolved in 1 liter of distilled water by heating. The dissolved components were autoclaved at $121^{\circ} \mathrm{C}$ for 15 minutes and left to cool to $45-50^{\circ} \mathrm{C}$ and just prior to pouring, $1 \mathrm{ml}$ of $1 \%$ sterilized potassium tellurite and $1 \mathrm{ml}$ of 200 units $/ \mathrm{ml}$ sterilized bacitracin were added. Sterilization of potassium tellurite and bacitracin was performed by filtration through millipores bacterial filters. About $20 \mathrm{ml}$ of the medium was poured in each Petri plate, all allowed to solidify at room temperature and then stored in the refrigerator at $4^{\circ} \mathrm{C}$ for no more than four weeks. Identification of oral S. Mutans was confirmed by biochemical tests like mannitol and sorbitol fermentation and catalase [64] colony counting was done with a magnifying glass and the count of S. Mutans was expressed as the number of colony forming units per milliliter (cfu/ $\mathrm{ml}$ ) of saliva. Semi quantitation of the number of colonies was done by multiplying the actual colony count with $1 \times 105$ because of the part that the saliva sample was diluted one thousand times 1:5 dilution $[65,66]$.

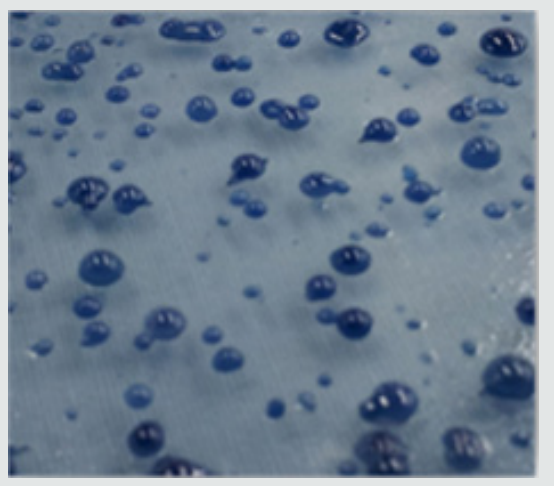

Figure 6: Mitis Salivarius agar media (Becton Dickinson and Difco Company, Chicago, USA), for isolation of S. mutans.

b) Lactobacillus Acidophilus Count: Second part of saliva sample were incubated on Tomato agar media for isolation of Lactobacilli for $1 \mathrm{~L}$ of medium dissolve in distilled water [67]. Tomato agar media contains: (Glucose 10.0gm, Yeast extract 5.0gm, Polypeptone $5.0 \mathrm{gm}, \mathrm{KH}_{2} \mathrm{PO}_{4} 0.5 \mathrm{gm}, \mathrm{KCl} 0.125 \mathrm{gm}, \mathrm{CaCl}_{2} .2 \mathrm{H}_{2} \mathrm{O}$ $0.125 \mathrm{gm}, \mathrm{NaCl} 0.125 \mathrm{gm}, \mathrm{MgSO}_{4} \cdot 7 \mathrm{H}_{2} \mathrm{O} 0.125 \mathrm{gm}, \mathrm{MnSO}_{4} \cdot 4 \mathrm{H}_{2} \mathrm{O}$ $0.003 \mathrm{gm}$, Bromocresol green 0.03gm, Canned tomato juice $150.0 \mathrm{ml}$ ). The ingredients were heated to dissolve the components, autoclaved at $121^{\circ} \mathrm{C}$ for 15 minutes and left to cool. Approximately $20 \mathrm{ml}$ of the medium was poured into each Petri plate and left to solidify at room temperature, then stored in refrigerator at $4^{\circ} \mathrm{C}$ until used. Plates were incubated within an anaerobic jar containing gas pack in the incubator for $2-4$ days at $37^{\circ} \mathrm{C}$. Lactobacilli were identified by colonial morphology catalase test and Gram stainingbinding agents (calcium carbonate) that confirmed it [68]. (Figure 7) Colony counting was done with a magnifying glass and the count of S. mutans and Lactobacilli was expressed as the number of colony forming units per milliliter $(\mathrm{cfu} / \mathrm{ml})$ of saliva. Semi quantitation of the number of colonies was done by multiplying the actual colony 
count with $1 \times 10^{5}$ because of the part that the saliva sample was diluted one thousand times 1:5 dilution [69].

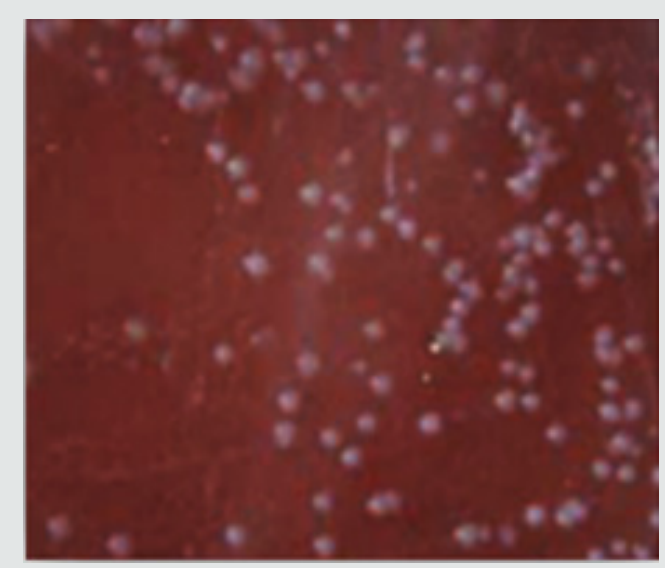

Figure 7: Tomato agar media for isolation of lactobacillus.

\section{Chemical Tests}

The $3^{\text {rd }}$ part of collected saliva sample was processed to measure the salivary urea level was measured by U.V. method with (ELI TECH kit) using autoanalyzer system (Advia 1650), salivary alkaline phosphatase level was measured by kinetic method (SERA-
PAK® kit) using (Advia 1650, salivary Calcium and phosphorous level by (ELI TECH kit) using micro lab analyzer spictrophoton (Micro lab 300).

\section{a) Salivary $\mathrm{pH}$ and Buffering Capacity}

Last part of saliva samples used to measure salivary $\mathrm{pH}$ by using pH meter [70] (pH 18 Aqua Lytic Co, USA). Buffering capacity is determined by quantitative test using a handheld. This method involves the addition of $0.5 \mathrm{ml}$ of saliva to $1.5 \mathrm{ml}$ of $5 \mathrm{M} \mathrm{HCl}$. Mixture was vigorously shaken. Then stream of Nitrogen was passed through the mixture for 20 minutes to eliminate carbon dioxide from the sample and allowed to stand for $10 \mathrm{~min}$ when the final $\mathrm{pH}$ is measured [71].

\section{Pilot Study}

A pilot study was first conducted to establish intra-examiner reliability. ten children were selected from outpatient dental clinic for that purpose. They were examined using the dental indices (deft, DMFT, GI and PI) and subsequently recorded by the examiner and scored by the same examiner. All the patients were re-examined after $24 \mathrm{~h}$. Kappa values were more than $89 \%$ for all indices, indicating good reliability.

\section{Result}

Table 5: Shows the mean values, standard deviations and the statistical analysis of for sex and age.

\begin{tabular}{|c|c|c|c|c|c|c|c|}
\hline & & & G 1 & G 2 & Total & $\chi^{2}$ & p-value \\
\hline \multirow{4}{*}{ Sex } & \multirow{2}{*}{ Male } & $\mathrm{n}$ & 24 & 27 & 51 & \multirow{6}{*}{1.288} & \multirow{6}{*}{$>0.05 \mathrm{NS}$} \\
\hline & & $\%$ & $-48 \%$ & $-54 \%$ & $-51 \%$ & & \\
\hline & \multirow{2}{*}{ Female } & $\mathrm{n}$ & 26 & 23 & 49 & & \\
\hline & & $\%$ & $-52 \%$ & $-46 \%$ & $-49 \%$ & & \\
\hline \multirow{2}{*}{\multicolumn{2}{|c|}{ Total }} & $\mathrm{n}$ & 50 & 50 & 100 & & \\
\hline & & $\%$ & $-50 \%$ & $-50 \%$ & $-100 \%$ & & \\
\hline \multirow[t]{2}{*}{ Age } & \multicolumn{3}{|c|}{ Group 1} & Group 2 & T-value & \multicolumn{2}{|c|}{ P-value } \\
\hline & \multicolumn{3}{|c|}{$8.7 \pm 3.03$} & $8.91 \pm 3.03$ & 0.73 & \multicolumn{2}{|c|}{$>0.05 \mathrm{NS}$} \\
\hline
\end{tabular}

Insignificant differences $(\mathrm{p}>0.05)$ NS

Data were checked, entered and analyzed by using SPSS (version 25). Data were presented as mean and Standard Deviation (SD) or quantitative variable. The qualitative data were presented as numbers and percentages and the Chi square test was used for comparison between groups. The quantitative data were presented as mean \pm standard deviation and the Student t-test was used for comparison between the groups. The following formulae were used in statistical analysis of results at level of significant 0.05 . Normality was tested using the Shapiro-Wilk test. (Table 5) shows the characteristics of study participants. No group differences were found in participant age and sex $(P>0.05)$. Since no statistically significant differences were found between sex and age so that, data were combined for them. Table 6 shows that salivary concentration of $\mathrm{Ca}$, Phosphorous, alkaline and phosphatase which these values did not differ between the two groups $(\mathrm{P}>0.05)$. On the other side, the salivary $\mathrm{pH}$, S. mutans and Lactobacillus count were significantly higher in salivary samples obtained from study group $(\mathrm{P}<0.001)$. Additionally, buffering capacity were significantly higher $(\mathrm{P}<$ 0.05 ) in study group. PI were significantly higher in study group $(\mathrm{P}<0.05)$, however, dmft and DMFT were significantly higher in control group $(\mathrm{P}<0.001)$ and GI did not differ between both groups $(\mathrm{P}>0.05)$. (Table 7$)$ shows the study group had significantly more enamel hypoplasia (46\%) than the control group (6\%). The presence of extrinsic stain and intrinsic stain is statically increase in study group $(\mathrm{P}<0.05)$. All ages with the disease duration of less than one year showed no clinical evidence of enamel hypoplasia, and the oldest age group, from 6 to 12 years, showed the highest number of enamel hypoplasia records (eleven patients) (Table 5). 
Table 6: Shows the mean values, standard deviations and the statistical analysis of the oral variables using the Student t-test.

\begin{tabular}{|c|c|c|c|}
\hline Oral variable & G1 & G2 & P-value \\
\hline Ca (mg/dl) & $14.786 \pm 6.17$ & $15.22 \pm 6.31$ & $>0.05 \mathrm{NS}$ \\
\hline Phosphorous (mg/dl) & $28.12 \pm 10.57$ & $30.08 \pm 8.686$ & $>0.05$ NS \\
\hline Alkaline Phosphatase (U/L) & $32.5 \pm 7.299$ & $30.98 \pm 12.55$ & $<0.05$ NS \\
\hline Urea (mg/dl) & $68.52 \pm 15.03$ & $80.56 \pm 22.07$ & $<0.001^{* *}$ \\
\hline pH & $6.514 \pm 0.688$ & $7.06 \pm 0.705$ & $<0.05^{*}$ \\
\hline Buffering capacity & $2.136 \pm 0.361$ & $2.215 \pm 0.185$ & $<0.001^{* *}$ \\
\hline S. mutans (x10 $/ \mathrm{ml})$ & $11.95 \pm 4.57$ & $6.47 \pm 2.8$ & $<0.001^{* *}$ \\
\hline Lactobacillus (x10 $/ \mathrm{ml})$ & $1.76 \pm 0.4$ & $0.48 \pm 0.19$ & $<0.001^{* *}$ \\
\hline dmft & $6.905 \pm 4.154$ & $3.595 \pm 3.116$ & $<0.001^{* *}$ \\
\hline DMFT & $2.675 \pm 2.539$ & $0.729 \pm 0.99$ & $>0.05 \mathrm{NS}$ \\
\hline Gingival Index GI & $1.06 \pm 0.866$ & $1.1 \pm 0.931$ & $<0.05^{*}$ \\
\hline Plaque Index PI & $1.32 \pm 0.793$ & $1.76 \pm 0.656$ & \\
\hline
\end{tabular}

Significant differences $(\mathrm{P}<0.05)$ *

Highly significant differences $(\mathrm{P}<0.001)$ **

Insignificant differences $(\mathrm{p}>0.05)$ NS

Table 7: Distribution of tooth discoloration and enamel hypoplasia in study and control groups using Chi-square test.

\begin{tabular}{|c|c|c|c|c|c|c|c|c|c|c|}
\hline \multicolumn{6}{|c|}{ Discoloration (\%) } & \multicolumn{5}{|c|}{ Hypoplasia (\%) } \\
\hline & & Non & Intrinsic & Extrinsic & Total & Non & Mild & Moderate & Severe & Total \\
\hline \multirow{2}{*}{ G 1} & $\mathrm{n}$ & 45 & 4 & 1 & 50 & 47 & 2 & 1 & 0 & 50 \\
\hline & $\%$ & $90 \%$ & $8 \%$ & $2 \%$ & $100 \%$ & $94 \%$ & $4 \%$ & $2 \%$ & $0 \%$ & $100 \%$ \\
\hline \multirow{2}{*}{ G 2} & $\mathrm{n}$ & 19 & 11 & 20 & 50 & 27 & 10 & 10 & 3 & 50 \\
\hline & $\%$ & $38 \%$ & $22 \%$ & $40 \%$ & $100 \%$ & $54 \%$ & $20 \%$ & $20 \%$ & $6 \%$ & $100 \%$ \\
\hline \multirow{2}{*}{ Total } & $\mathrm{n}$ & 64 & 15 & 24 & 100 & 74 & 12 & 11 & 3 & 100 \\
\hline & $\%$ & $64 \%$ & $15 \%$ & $24 \%$ & $100 \%$ & $74 \%$ & $12 \%$ & $11 \%$ & $3 \%$ & $100 \%$ \\
\hline$x^{2}$ & \multicolumn{5}{|c|}{31.01} & \multicolumn{5}{|c|}{21.01} \\
\hline $\mathrm{p}$-value & \multicolumn{5}{|c|}{$<0.05^{*}$} & \multicolumn{5}{|c|}{$<0.05^{*}$} \\
\hline
\end{tabular}

Significant differences $(\mathrm{P}<0.05)$ *

Table 8: Distribution of children in study group with enamel hypoplasia, according to the age of onset and duration of the disease.

\begin{tabular}{|c|c|c|c|c|c|c|}
\hline \multirow{2}{*}{ Onset and duration of the disease } & \multicolumn{3}{|c|}{ No. of children in G2 } & \multicolumn{3}{|c|}{ No. of children with hypoplasia } \\
\hline & $2-6 y$ & $>6-12 y$ & $>12-15 y$ & $2-6 y$ & $>6-12 y$ & $>12-15 y$ \\
\hline 1 year & 4 & 4 & 2 & - & - & - \\
\hline$>1-4$ year & 7 & 21 & 4 & 2 & 11 & 3 \\
\hline$>4$ year & 1 & 5 & 2 & - & 5 & 2 \\
\hline Total & 12 & 30 & 8 & 2 & 16 & 5 \\
\hline
\end{tabular}


Table 9: Daily tooth-brushing frequency (\%) and dental check-up frequency in study and control group using Chi-square test.

\begin{tabular}{|c|c|c|c|c|c|c|}
\hline \multirow{2}{*}{$\mathrm{No}=50$} & \multicolumn{3}{|c|}{ Daily Tooth Brushing (\%) } & \multicolumn{3}{|c|}{ Periodic Dental Check-Up (\%) } \\
\hline & & Non & Once daily at least & Non & Rare & Regular \\
\hline \multirow{2}{*}{ G 1} & No & 45 & 5 & 46 & 3 & 2 \\
\hline & $\%$ & $90 \%$ & $10 \%$ & $92 \%$ & $6 \%$ & $4 \%$ \\
\hline \multirow{2}{*}{ G 2} & No & 44 & 6 & 48 & 1 & 1 \\
\hline & $\%$ & $88 \%$ & $12 \%$ & $96 \%$ & $2 \%$ & $2 \%$ \\
\hline$\chi^{2}$ & \multicolumn{3}{|c|}{0.102} & \multicolumn{3}{|c|}{1.43} \\
\hline $\mathrm{p}$-value & \multicolumn{3}{|c|}{$>0.05 \mathrm{NS}$} & \multicolumn{3}{|c|}{$>0.05 \mathrm{NS}$} \\
\hline
\end{tabular}

Insignificant differences $(\mathrm{p}>0.05) \mathrm{NS}$

\section{Discussion}

In the present study, the 50 children with ESRD clearly differed from a normal childhood population in most of the dental parameters increase such as enamel hypoplasia, tooth discoloration, S. mutans and lactobacilli counts, salivary $\mathrm{pH}$, salivary urea level and buffer capacity of saliva. However, the chemistry of saliva denoted that there were insignificance differences in salivary $\mathrm{Ca}$, phosphorus and Alkaline phosphatase levels (Table 6). The low caries prevalence which recorded by low dmft, DMFT in CRF children was the most interesting finding of this study, although the patients had poor oral hygiene and were maintained on high-carbohydrate diets that agrees with earlier work [72-74]. Salivary urea elevated salivary $\mathrm{pH}$, possibly negating the effect of any acid formation by these cariogenic bacteria resulting from sugar intake. This mechanism also inhibits caries because of its antibacterial properties and its inhibitory effect on plaque formation. In addition, high salivary phosphate concentrations found in patients with uremia may facilitate remineralization of incipient carious lesions [72]. So that, both the mean dmft and DMFT were significantly lower in the CRF children, which agrees with earlier work $[72,73]$. The prevalence of the caries was reduced despite poor oral hygiene in uremic children (Table 7). This is most likely because of increasing both salivary urea concentration that raise salivary $\mathrm{pH}$, which may inhibit the growth of S. mutans and lactobacillus. In many reports, there is a positive correlation between dental caries and S. mutans, and lactobacilli counts $[74,75]$. The total count of S. mutans and lactobacillus, in present study, were significantly decreased in CRF patients than control group that agrees with earlier work [76]. Some other authors [77-79] have reported that, the total count of S. mutans was significantly greater in the control group compared with CRF children and there was no significant difference in number of lactobacilli of either CRF or control group. Our clinical finding revealed that $46 \%$ of the patients demonstrated various degrees of enamel defects, compared to Wolff [80] study $47.4 \%$, in the form of hypoplasia. This increase in hypoplasia prevalence was probably due to abnormal calcium and phosphate metabolism. The enamel hypoplasia in CRF patients was significantly increased $(\mathrm{P}>0.05)$.
As regards frequency of enamel hypoplasia, in this finding, there was $94 \%$ had no hypoplasia, $4 \%$ had mild hypoplasia and $2 \%$ had moderate hypoplasia in G1 while there was 54\% had no hypoplasia, $20 \%$ had mild hypoplasia, 20\% had moderate hypoplasia and $6 \%$ sever hypoplasia in study group. These reports agreed with earlier workers [72,84]. Also, Nunn JH et al. [72] reported that, $83 \%$ of their renal patients had enamel defects. Many authors [72,81] stated that, calcium depletion with renal impairment during mineralization of the developing dentition, often resulting in enamel hypoplasia, is a likely sequela. There was an evident correlation between the location on the teeth of hypoplastic changes and the age of onset of severe renal failure, which was like the findings of (Table 8). Koch MJ et al. [82] who investigated the exfoliated primary teeth of CRF or ESRD patients microscopically and showed that enamel hypoplasia was limited to postnatal enamel, and hypoplasia increases with the duration of the disease and the early onset. Tooth discoloration was increased in CRF patients significantly. The stain may be intrinsic or extrinsic (Table 8). Extrinsic stain can be readily removed from the surface of the teeth with an abrasive prophylactic material. As regards frequency of tooth discoloration (\%) in present study, there was $90 \%$ had not discoloration, $8 \%$ had intrinsic discoloration and $2 \%$ had extrinsic discoloration in control group while there was $38 \%$ had no discoloration, $22 \%$ had intrinsic discoloration and $40 \%$ had extrinsic discoloration in study group. There were significant differences between both groups as regards all items $(\mathrm{P}<0.05)$. Intrinsic staining is generally a result of adsorption of pathological pigments onto the dentine matrix. Brown discoloration can be seen when uremia is present during development of the dentitions. Intrinsic stains are also seen in some haemodialysis patients resulting from the use of tetracycline to treat infection during the period of calcification of the primary and permanent teeth. Intrinsic stains in our study group were not related to tetracycline use since the patients' physicians were aware that tetracycline could stain developing teeth and did not prescribe it. Our findings of intrinsic brown staining in $22 \%$ of patients may be due to the presence of uremia during the development of the dentitions; this agrees with previous reports $[81,84]$. The children with CRF were being treated for anemia with ferrous sulfate in syrup form, which caused the 
black-brown extrinsic staining on the teeth [73]. Although, the mean of Plaque Index score was significantly greater in the CRF children compared with the controls, there was no significant difference in gingival inflammation, which agrees with results of earlier researchers [72,84-86]. The gingiva in individuals with CRF can be pale due to anemia, with possible loss of the demarcation of the mucogingival junction and when there is platelet dysfunction, the gingiva may bleed easily [87-90]. This is attributed to a modified tissue response because of immunocompromised. In addition, anemia is a common problem in patients with CRF and it is possible that gingival inflammation is masked by the paleness of the gingiva. However, another study revealed that, accelerated periodontal disease in patients with renal failure, possibly related to impaired white cell function [91]. Jaffe EC et al. [73] who found that, plaque amounts were similar in both groups, but the gingival status was lower for the ESRD patients. Davidovich et al. [49] reported that, the patients suffering from (ESRF) and those receiving dialysis are more prone to periodontal disease and other oral health problems. The renal failure patients had higher gingival index (GI) and bleeding; probing depths, attachment loss, hypoplasia, obliteration and less caries. It appears that patients with uremia undergoing haemodialysis have a reduced gingival inflammatory response to bacterial dental plaque compared with the controls. As regards daily tooth brushing (\%) and periodic dental check-up (\%), in present study, there was $90 \%$ not perform tooth brushing at all and $10 \%$ performing it once daily in control group while there was $88 \%$ not perform tooth brushing at all and $12 \%$ performing it once daily at least in patients group with insignificant difference in oral health status between both groups ( $\mathrm{P}>0.05)$. There was $92 \%$ not perform periodic dental check-up at all 6\% perform it rarely and $4 \%$ perform it regularly in control group while there was $96 \%$ not perform periodic dental check-up at all, $2 \%$ perform it rarely and $2 \%$ perform it regularly in study the group with insignificant difference between both groups $(\mathrm{P}>0.05)$. It is likely to relation between the patients' level of education and low socioeconomic status (Table 9). These findings indicate that there is a need for dental health education for all children and their parents.

\section{Conclusion}

The proportion of CRF children with dental caries was significantly less than for the matched controls. This is most likely because of a greater salivary urea concentration and high $\mathrm{pH}$ and buffering capacity, which may inhibit the growth of S. mutans and lactobacillus. The increased plaque score in both the primary dentition and permanent dentition and gingival changes suggest a need for dental advice and supervision beside the general medical care is needed by these children.

\section{Recommendation}

The incorporation of a dental service into the general medical program would benefit these children. Effective tooth brushing from an early age would help to prevent the development of periodontal disease, as adults would also be minimized. Awareness must be raised among CRF patients, their nephrologists and their dentists about the need for primary dental prevention. See the patient for dental check-ups as regularly as would be the case if they were not undergoing dialysis.

\section{Acknowledgement}

The authors wish to thank all children, participants and their parents or guardians for their valuable participation in this study. This study was supported clinically by all staff of pediatric department, clinical pathology department and microbiology department of Faculty of Medicine in Zigzag University. We would like to thank Professor Ali MM Abu Zeid, Professor of Pediatric Department Zigzag University and Professor. Samy Y. Elbayoumy, Head of Pedodontic and Dental Public Health Department, Faculty of Dental medicine, Al-Azhar University for their continuous encouragement, cooperation and support. This study was supported by self-fund of authors.

\section{References}

1. Francesca Becherucci, Rosa Maria Roperto1, Marco Materassi, and Paola Romagnani (2016) Chronic kidney disease in children. Clinical Kidney Journal 9(4): 583-591.

2. Lysaght MJ (2002) Maintenance dialysis population dynamics: current trends and long-term implications. J Am Soc Nephrol 13(Supp 1): 3740.

3. Brück K, Stel VS, Fraser S, M Goeij, F Caskey, et al. (2015) Translational research in nephrology: chronic kidney disease prevention and public health. Clin Kidney J 8(6): 647-655.

4. Maalej B, Louati H, Guirat R, Wali M, Abid H, et al. (2018) Childhood Chronic Kidney Disease: Experience of a Pediatric Department. J Nephrol Urol 2(1): 1.

5. Warady BA, Chadha V (2007) Chronic kidney disease in children: The global perspective. Pediatr Nephrol 22(12): 1999-2009.

6. Jérôme Harambat, Karlijn J van Stralen, Jon Jin Kim, E Jane Tizard (2012) Epidemiology of chronic kidney disease in children. Pediatr Nephrol 27(3): 363-373.

7. Ardissino G, Daccò V, Testa S, Bonaudo R, Claris Appiani A, et al. (2003) Epidemiology of chronic renal failure in children: data from the ItalKid project. Pediatrics 111(4 Pt 1): 382-387.

8. Fivush BA, Jabs K, Neu AM, Sullivan EK, Feld L, et al. (1998) Chronic renal insufficiency in children and adolescents: the annual report of NAPRTCS. North American Pediatric Renal Transplant Cooperative Study. Pediatr Nephrol 12(4): 328-337.

9. Deleau J, Andre JL, Briancon S, Musse JP (1994) Chronic renal failure in children: an epidemiological survey in Lorraine (France) 1975-1990. Pediatr Nephrol 8(4): 472-476.

10. Al Eisa A, Naseef M, Al Hamad N, Pinto R, Al Shimeri N, et al. (2005) Chronic renal failure in Kuwaiti children: an eight-year experience. Pediatr Nephrol 20(12): 1781-1785.

11. Hogg RJ, Furth S, Lemley KV, Portman R, Schwartz GJ, et al. (2003) National Kidney Foundation's Kidney Disease Outcomes Quality Initiative clinical practice guidelines for chronic kidney disease in children and adolescents: Evaluation, classification, and stratification. Pediatrics 111(6): 1416-1421.

12. (2008) North American Pediatric Renal Transplant Cooperative Study (NAPRTCS) Annual report. The EMMES Corporation, Rockville. 
13. (2010) US Renal Data System, USRDS Annual data report: atlas of chronic kidney disease and end-stage renal disease in the United States. National Institutes of Health, National Institute of Diabetes and Digestive and Kidney Diseases, Bethesda.

14. Mong Hiep TT, Ismaili K, Collart F, Van Damme Lombaerts R, Godefroid N, et al. (2010) Clinical characteristics and outcomes of children with stage 3-5 chronic kidney disease. Pediatr Nephrol 25(5): 935-940.

15. Hamed RM (2002) The spectrum of chronic renal failure among Jordanian children. J Nephrol 15(2): 130-135.

16. Bek K, Akman S, Bilge I, Topaloğlu R, Calişkan S, et al. (2009) Chronic kidney disease in children in Turkey. Pediatr Nephrol 24(4): 797-806.

17. Afifi A, Karim MA (1999) Renal replacement therapy in Egypt: first annual report of the Egyptian Society of Nephrology. East Mediterr Health J 5(5): 1023-1029.

18. Afifi AM, Mady GE, Ahmad AA, El Shar Kawy ME, Aly AR, et al. (2005) Pattern of renal diseases among elderly Egyptians patients with acute or chronic renal diseases in Ain Shams University and Nasser Institute Hospitals, Cairo, Egypt. J Egypt Soc Parasitol 35(3): 911-924.

19. Barsoum R (1996) Dialysis in developing countries. In: Jacobs C, Kjellstrand CM, Koch KM, Winchester JF[Edt.], Replacement of renal function by dialysis. Kluwer, London.

20. Gulati S, Mittal S, Sharma RK, Gupta A (1999) Etiology and outcome of chronic renal failure in Indian children. Pediatr Nephrol 13(7): 594596.

21. Ali el TM, Abdelraheem MB, Mohamed RM, Hassan EG, Watson AR (2009) Chronic renal failure in Sudanese children: aetiology and outcomes. Pediatr Nephrol 24(2): 349-353.

22. Hattori S, Yosioka K, Honda M, Ito H (2002) Japanese Society for Pediatric Nephrology The 1998 report of the Japanese National Registry data on pediatric end-stage renal disease patients. Pediatr Nephrol 17(6): 456-461.

23. Orr NI, McDonald SP, McTaggart S, Henning P, Craig JC (2009) Frequency, etiology and treatment of childhood end-stage kidney disease in Australia and New Zealand. Pediatr Nephrol 24(9): 17191726.

24. Seikaly MG, Salhab N, Gipson D et al. (2006) Stature in children with chronic kidney disease: analysis of NAPRTCS database. Pediatr Nephrol 21(6): 793-799.

25. Rodig NM, McDermott KC, Schneider MF, Hotchkiss HM, Yadin O et al. (2014) Growth in children with chronic kidney disease: a report from the chronic kidney disease in children study. Pediatr Nephrol 29(10): 1987-1995.

26. Rees L (2015) Growth hormone therapy in children with CKD after more than two decades of practice. Pediatr Nephrol 31(9): 1421-1435.

27. Gat Yablonski G, Phillip M (2015) Nutritionally-induced catch-up growth. Nutrients 7(1): 517-551.

28. Sanchez CP, Salusky IB, Kuizon BD, Abdella P, Jüppner H, et al. (1998) Growth of long bones in renal failure: roles of hyperparathyroidism, growth hormone and calcitriol. Kidney Int 54(6): 1879-1887.

29. Rees L, Mak RH (2011) Nutrition and growth in children with chronic kidney disease. Nat Rev Nephrol 7(11): 615-623.

30. Fraenkel PG (2015) Understanding anemia of chronic disease. Hematology Am Soc Hematol Educ Program: 14-8.

31. Gerson A, Hwang W, Fiorenza J et al. (2004) Anemia and health-related quality of life in adolescents with chronic kidney disease. Am J Kidney Dis 44: 1017-1023.

32. Atcliffe LE, Thomas W, Glen J, Padhi S, Pordes BA, et al. (2016) Diagnosis and management of iron deficiency in CKD: a summary of the NICE guideline recommendations and their rationale. Am J Kidney Dis 67(4): 548-558.
33. Flynn JT, Mitsnefes M, Pierce C, Cole SR, Parekh RS, et al. (2008) Blood pressure in children with chronic kidney disease: a report from the Chronic Kidney Disease in Children study. Hypertension 52(4): 631637.

34. Mitsnefes MM (2012) Cardiovascular disease in children with chronic kidney disease. J Am Soc Nephrol 23(4): 578-585.

35. Mitsnefes M, Flynn J, Cohn S et al. (2010) Masked hypertension associates with left ventricular hypertrophy in children with CKD.J Am Soc Nephrol 21(1): 137-144.

36. Sarnak MJ, Levey AS, Schoolwerth AC, Coresh J, Culleton B et al. (2003) Kidney disease as a risk factor for development of cardiovascular disease: a statement from the American Heart Association Councils on Kidney in Cardiovascular Disease, High Blood Pressure Research, Clinical Cardiology, and Epidemiology and Prevention. Hypertension 42(3): 1050-1065.

37. Shroff R, Dégi A, Kerti A (2013) Cardiovascular risk assessment in children with chronic kidney disease. Pediatr Nephrol28: 875-888.

38. Safder O, Al sharif S, Kari JA (2014) Pediatric CKD and cardiovascular disease. Cardiovasc Hematol Disord Drug Targets 14(3): 177-184.

39. Lilien MR, Groothoff JW (2009) Cardiovascular disease in children with CKD or ESRD. Nat Rev Nephrol 5(4): 229-235.

40. Wesseling Perry K, Salusky IB (2013) Chronic kidney disease: mineral and bone disorder in children. Semin Nephrol 33(2): 169-179.

41. Wesseling Perry K (2013) Bone disease in pediatric chronic kidney disease. Pediatr Nephrol 28(4): 569-576.

42. Gansevoort RT, Correa Rotter R, Hemmelgarn BR (2013) Chronic kidney disease and cardiovascular risk: epidemiology, mechanisms, and prevention. Lancet 382: 339-352.

43. Rees L, Shroff R (2015) The demise of calcium-based phosphate binders-is this appropriate for children? Pediatr Nephrol 30: 20612071.

44. Levy HM (1988) Dental considerations for the patient receiving dialysis for renal failure. Spec Care Dentist 8(1): 34-36.

45. Chatenoud L, Jungers P, Descamps Latscha B (1994) Immunological considerations of the uremic and dialyzed patient. Kidney Int Suppl 44: 92-96.

46. Epstein SR, Mandel I, Scopp IW (1980) Salivary composition, and calculus formation in patients undergoing haemodialysis. J Periodontol 51: 336-338.

47. Wysocki GP, Daley TD, Ulan RA (1983) Predentin changes in patients with chronic renal failure. Oral Surg Oral Med Oral Pathol 56: 167- 73.

48. Nasstrom K, Forsberg B, Petersson A, Westesson PL (1985) Narrowing of the dental pulp chamber in patients with renal diseases. Oral Surg Oral Med Oral Pathol 59: 24 2-246.

49. Davidovich E, Schwarz Z, Davidovitch M, Eidelman, E Bimstein E (2005) Oral findings and periodontal status in children, adolescents and young adults suffering from renal failure J Clin Period 32(10): 1076-1082.

50. Gold OG, Jordan HV, Van Houte J (1973) A selective medium for S. mutans. Arch Oral Biol 18(11): 1357-1364.

51. Shasha SM, Ben Aryeh H, Angel A, Gutman D (1983) Salivary content in hemodialyzed patients. J Oral Med 38(2): 67-70.

52. Kho HS, Lee SW, Chung SC, Kim YK (1999) Oral manifestations andsalivary flow rate, $\mathrm{pH}$ and buffer capacity in patients with endstage renal disease undergoing haemodialysis. Oral Surg Oral Med Oral Pathol Oral Radiol Endod 88(3): 316-9.

53. Tulunoglu 0, Demirtas S, Tulunoglu I (2006) Total antioxidant levels of saliva in children related to caries, age and gender. Int J Paediatr Dent 16(3): 186-91. 
54. Greenberg MS, Cohen G (1977) Oral infection in immunosuppressed renal transplant patients. Oral Surg Oral Med Oral Pathol 43: 879-885.

55. Bottomley WK, Cioffi RF, Martin AJ (1972) Dental management of the patient treated by renal transplantation: preoperative and postoperative considerations. J Am Dent Assoc 85: 1330-1335

56. Naylor GD, Hall EH, Terezhalmy GT (1988) The patient with chronic renal failure who is undergoing dialysis or renal transplantation another consideration for antimicrobial prophylaxis. Oral Surg Oral Med Oral Pathol 65 (1): 116-121.

57. World Medical Association (2013) World Medical Association Declaration of Helsinki, Ethical Principles for Medical Research, Involving Human Subjects. J Amer Medi Asso 310(20): 2191-2194.

58. World Health Organization (1987) Oral Health Surveys: Basic Methods ( $3^{\text {rd }}$ edn) Geneva, Switzerland 334-335.

59. World health organization (WHO) (1987) Prevention of oral disease. Geneva, Switzerland.

60. Löe H, Silness J (1963) Periodontal disease in pregnancy- I. Prevalence and Severity. Acta Odontol Scand 21: 533-551.

61. Silness P, Löe H (1964) Periodontal disease in pregnancy - II Correlation between oral hygiene and periodontal condtion. Acta Odontol Scand 2: 121-135.

62. Alaluusa S, Lukinmaa PL, Koskimies M, Pirinen S, Holtta P, et al. (1996) Developmental dental defects associated with long breast-feeding. Eur J Oral Sci 104(5-6): 493-497.

63. Gold O, Jordan H, Van Houte J (1973) A selective medium for S. mutans. Arch Oral Biol 18(11): 1357-1364.

64. Beighton D, Russell R, Whiley R (1991) A simple biochemical scheme for the differentiation of Streptococcus mutans and Streptococcus sobrinus. Caries Res 25(3): 174-178.

65. McGhee J, Michalek S, Cassell G (1982) Dental Microbiology Philadelphia: Harper and Row.

66. Beighton D (1986) A simplified procedure for estimating the level of Streptococcus mutans in the mouth. Br Dent J 160(9): 329-330.

67. Yoshizumi Yh, Carr JG, Cutting CV, Whiting G (1975) A malo-lactic bacterium and its growth factor in lactic acid bacteria in beverages and food etc. London, New York, and San Francisco: Academic Press 87-102.

68. Holt JR, Krieg NR, Sneath PH, Staley JT, Williams ST (1994) Bergey's Manual of Determinative Bacteriology, ( $9^{\text {th }}$ edn). Williams and Wilkins, Baltimore, Maryland, USA.

69. McGhee JR, Michalek SM, Cassell GH (1982) Dental Microbiology Philadelphia: Harper and Row 74: 681.

70. Kitasako Y, Moritsuka M, Foxton R M, Ikeda M, Tagami J, et al. (2005) Simplified and quantitative saliva buffer capacity test using a handheld pH meter. AM J Dentist 18(3):147-150.

71. Moritsuka M, Kitasako Y, Burrow MF, Ikeda M, Tagami J (2006) The $\mathrm{pH}$ change after $\mathrm{HCl}$ titration into resting and stimulated saliva for a buffering capacity test. Aust Dent J 51(2): 170-174.

72. Nunn JH, Sharp J, Lambert HJ, et al. (2000) Oral health in children with renal disease. Pediatr Nephrol 14(10-11): 997-1001.
73. Jaffe EC, Chantler Carter JE (1986) Dental findings in chronic renal failure. Br Dent J 160(1): 18-21.

74. Chow MH, Peterson DS (1979) Dental management for children with chronic renal failure undergoing hemodialysis therapy. Oral Surg 48(1): 34-38.

75. Ellis JS, Seymour RA, Monkman SC, Idle JR (1993) Disposition of nifedipine in plasma and gingival crevicular fluid in relation to drug induced gingival overgrowth. J Periodontal Res 28(5): 373-378.

76. Fahinur E, Cigdem, Ertugrul Sabah, Sevgi M (2003) The oral health status of children undergoing hemodialysis treatment. The Turkish Journal of Pediatrics 45: 108-113.

77. Al Nowaiser A, Roberts GJ, Trompeter RS, Wilson M, Lucas VS (2003) Oral health in children with chronic renal failure. Pediatr Nephrol 18: 39-45.

78. Loesche WJ (1986) Role of Streptococcus mutans in human dental decay. Microbiol Rev 50(4): 353-380.

79. Hanada N (2000) Current understanding of the cause of dental caries. Jpn J Infect Dis 53(1): 1-5.

80. Wolff A, Stark H, Sarnat H, Binderman I, Eisenstein B, et al. (1985) The dental status of children with chronic renal failure. Int J Pediatr Nephrol 6(2): 127-132.

81. Warady BA, Koch M, O'Neal DW, Higginbotham M, Harris DJ, et al. (1989) Plasma fluoride concentration in infants receiving long-term peritoneal dialysis. J Pediatr 115(3): 436-439.

82. Koch MJ, Buhrer R, Pioch T, Scharer K (1999) Enamel hypoplasia of primary teeth in chronic renal failure. Pediatr Nephrol 13(1): 68-72.

83. Sowell SB (1982) Dental care for patients with renal failure and renal transplants. J Am Dent Assoc 104(2): 171-177.

84. James JA, Boomer S, Maxwell AP, Hull PS, Short CD, et al. (2000) Reduction in gingival overgrowth associated with conversion from ciclosporin to a tacrolimus. J Clin Periodontol 27(2): 144-148.

85. Tollefsen T, Johansen JR (1985) The periodontal status of prospective and renal transplant patients. Comparison with systemically healthy subjects. J Periodontal Res 20(2): 220-226.

86. Moussa SA (2006) Dental health status in children with chronic renal failure. MSc. thesis in pediatric dentistry, Dental school, Al- Azhar University, Egypt.

87. Buckley DJ, Barrett AP, Koutts J, Stewart JH (1986) Control of bleeding in severely uremic patients undergoing oral surgery. Oral Surg Oral Med Oral Pathol 61(6): 546-549.

88. Lohr JW, Schwab SJ (1991) Minimizing hemorrhagic complications in dialysis patients. J Am Soc Nephrol 2(5): 961-975.

89. London GM, Drueke TB (1997) Atherosclerosis and arteriosclerosis in chronic renal failure. Kidney Int 51(6): 1678-1695.

90. Opatry K (1997) Hemostasis disorders in chronic renal failure. Kidney Intl 52(62): 87-89.

91. Carl W (1987) Chronic renal disease and hyperparathyroidism: dental manifestations and management. Compendium 8(9): 697-699, 702, 704. 
CC (P) This work is licensed under Creative Commons Attribution 4.0 License

To Submit Your Article Click Here: Submit Article

DOI: $10.32474 /$ IPDOAJ.2019.02.000141

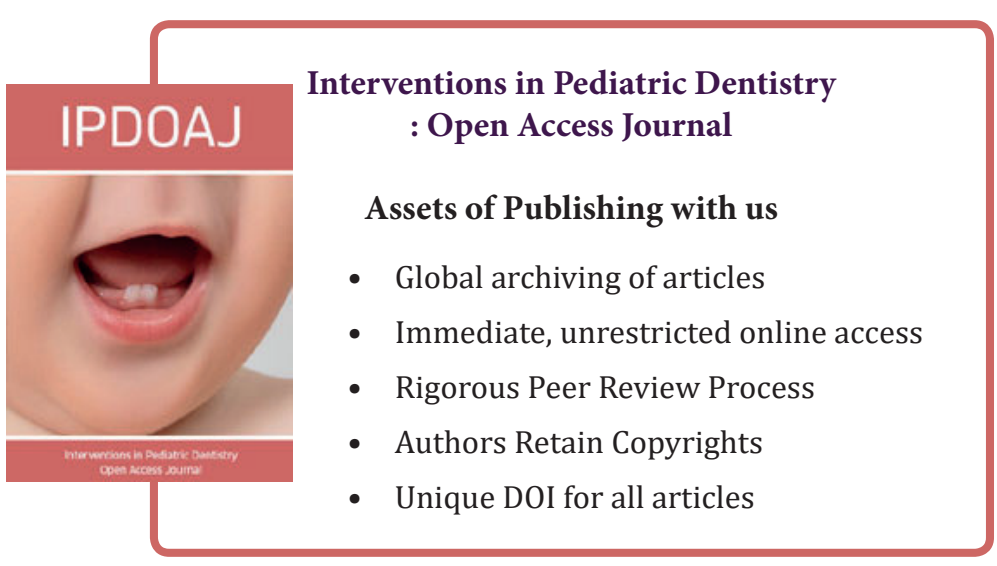

